\title{
Low-level seaweed supplementation improves iodine status in iodine-insufficient women
}

\author{
Emilie Combet*, Zheng Feei Ma, Frances Cousins, Brett Thompson and Michael E. J. Lean \\ Human Nutrition, School of Medicine, College of Medical, Veterinary and Life Sciences, University of Glasgow, \\ New Lister Building, Alexandra Parade, Glasgow G31 2ER, UK \\ (Submitted 4 March 2014 - Final revision received 23 May 2014 - Accepted 27 May 2014 - First published online 9 July 2014)
}

\begin{abstract}
Iodine insufficiency is now a prominent issue in the UK and other European countries due to low intakes of dairy products and seafood (especially where iodine fortification is not in place). In the present study, we tested a commercially available encapsulated edible seaweed (Napiers Hebridean Seagreens ${ }^{\circledR}$ Ascophyllum nodosum species) for its acceptability to consumers and iodine bioavailability and investigated the impact of a 2-week daily seaweed supplementation on iodine concentrations and thyroid function. Healthy non-pregnant women of childbearing age, self-reporting low dairy product and seafood consumption, with no history of thyroid or gastrointestinal disease were recruited. Seaweed iodine $(712 \mu \mathrm{g}$, in $1 \mathrm{~g}$ seaweed) was modestly bioavailable at 33 (interquartile range (IQR) $28-46$ ) \% of the ingested iodine dose compared with 59 (IQR 46-74)\% of iodine from the KI supplement $(n$ 22). After supplement ingestion ( 2 weeks, $0 \cdot 5 \mathrm{~g}$ seaweed daily, $n$ 42), urinary iodine excretion increased from 78 (IQR 39-114) to 140 (IQR 103-195) $\mu \mathrm{g} / 1(P<0 \cdot 001)$. The concentrations of thyroidstimulating hormone increased from 1.5 (IQR $1 \cdot 2-2 \cdot 2)$ to $2 \cdot 1$ (IQR $1 \cdot 3-2 \cdot 9) \mathrm{mIU} / \mathrm{l}(P<0 \cdot 001)$, with two participants having concentrations exceeding the normal range after supplement ingestion (but normal free thyroxine concentrations). There was no change in the concentrations of other thyroid hormones after supplement ingestion. The seaweed was palatable and acceptable to consumers as a whole food or as a food ingredient and effective as a source of iodine in an iodine-insufficient population. In conclusion, seaweed inclusion in staple foods would serve as an alternative to fortification of salt or other foods with KI.
\end{abstract}

Key words: Iodine: Women: Seaweeds: Ascophyllum nodosum: Bioavailability: Thyroid function: Childbearing age

Iodine is essential for the synthesis of the thyroid hormones triiodothyronine $\left(\mathrm{T}_{3-}\right)$ and thyroxine $\left(\mathrm{T}_{4}\right)$, which play key roles in metabolism and are vital for a growing fetus and for normal growth and brain development ${ }^{(1)}$. Although hypothyroidism complicates some pregnancies ${ }^{(2)}$, it does not preclude hypothyroid women from becoming pregnant ${ }^{(3)}$, and iodine intake is crucial during the during the periods preceding and following pregnancy. When iodine intake is below the recommended value $\left(250 \mu \mathrm{g} / \mathrm{d}\right.$ during pregnancy ${ }^{(4)}$, although a new threshold value of $200 \mu \mathrm{g} / \mathrm{d}$ has been proposed $\left.{ }^{(5)}\right)$, adequate secretion of thyroid hormones may still be achieved by physiological adaptation. Modifications of thyroid and pituitary activities increase the secretion of thyroid-stimulating hormone (TSH), which enhances $\mathrm{T}_{3}$ production relative to $T_{4}$ and induces rapid iodine turnover ${ }^{(6)}$, but fetal supply and placental transfer remain low. For epidemiological purposes, iodine insufficiency is defined as median urinary excretion (urinary iodine concentration, UIC) $<100 \mu \mathrm{g} / 1$ for non-pregnant adults and $<150 \mu \mathrm{g} / \mathrm{l}$ for pregnant women within a population or a subgroup ${ }^{(4)}$. Although iodine fortification of common foods is widespread, it is not implemented in all countries. There is no requirement for iodine fortification of foods in the UK and iodine fortification is unusual. There is growing concern that subclinical iodine deficiency may be emerging in post-industrial countries previously assumed to be iodine sufficient, and there is currently very little evidence regarding the need for specific dietary advice or for iodine fortification/supplementation targeted towards the following two key vulnerable groups: young women and their infants.

With dairy products and seafood being the main dietary sources of iodine ${ }^{(7)}$, the UK has been considered iodine replete. In areas with historical endemic goitre ('Derbyshire neck'), there are no longer cases of clinical dietary hypothyroidism, hailed as an accidental public health success, following changes made to farming practice and supplementation of dairy herds ${ }^{(8)}$. However, a recent survey of British schoolgirls has highlighted mild iodine deficiency with median urinary iodine concentrations of $80 \mu \mathrm{g} / \mathrm{l}^{(9)}$. Similar results have been obtained

Abbreviations: IQR, interquartile range; NaHS, Napiers Hebridean Seagreens Ascophyllum nodosum; $\mathrm{T}_{3}$, triiodothyronine; $\mathrm{T}_{4}$, thyroxine; Tg, thyroglobulin; TSH, thyroid-stimulating hormone; UIC, urinary iodine concentrations.

*Corresponding author: E. Combet, email emilie.combetaspray@glasgow.ac.uk 
in a Scottish survey of women of childbearing age ${ }^{(10)}$. Although few people have frank iodine deficiency and hypothyroidism, a low or marginal intake presents a potential hazard during pregnancy due to the increased demand placed on maternal thyroid function ${ }^{(11)}$. This level of iodine insufficiency in a population is sufficient to impair the intellectual development of future generations. In the Avon Longitudinal Study of Parents and Children (ALSPAC) cohort of 1040 children from the south of England, Bath et al. ${ }^{(12)}$ showed that low maternal iodine status in pregnancy (individual iodine:creatinine ratios $<150 \mu \mathrm{g} / \mathrm{g}$ in spot samples) is associated with decreased cognitive functions. Although there is availability of dietary iodine in these regions ${ }^{(13)}$, the explanation for this may be that many of the young females commonly exclude fish and/or dairy products from their diets, for social or other reasons, leading to either low or marginal iodine intakes ${ }^{(14)}$.

Seaweeds used to feature as cheap and natural traditional foods in the British diet ${ }^{(15)}$ until recently. European standards have later been set to ensure their suitability as a human food. Despite this, this issue is still rather neglected throughout Europe, with little data being available on the range of seaweed products for sale in the UK or Europe (Norman et $a l .{ }^{(16)}$ mainly studied a range of kelp tablets, citing laverbread and Nori seaweed sheets as other seaweed products available). Data on their consumption are lacking, despite the fact that they are a rich source of iodine, with wide variations between species (from 16 to $8165 \mu \mathrm{g} / \mathrm{g}$ ) ${ }^{(17)}$.

The present study aimed to investigate the potential of seaweeds as safe and acceptable options for dietary iodine supplementation, specifically answering the following research questions:

(1) What is the iodine bioavailable from an encapsulated edible seaweed (Seagreens ${ }^{\circledR}$ Ascophyllum nodosum species) in a group of asymptomatic non-pregnant women reporting to consume low amounts of iodinerich foods?

(2) What is the impact of daily consumption of the encapsulated seaweed on iodine concentrations and thyroid function in the same group of women?

(3) Is the encapsulated seaweed acceptable to consumers (taste/use)?

\section{Materials and methods}

\section{Seaweed supplement}

Each capsule used in the study contained $0.5 \mathrm{~g}$ of Seagreens A. nodosum (Napiers Hebridean Seagreens (NaHS) capsules), equivalent to $356 \mu \mathrm{g}$ of iodine (supplier's information based on measurements by independent UKAS-accredited laboratories). NaHS is a dried and milled seaweed, sourced in Scotland and produced to distinct Human Food Seaweed ${ }^{\mathrm{TM}}$ standards (patents pending) ensuring the safety, quality, sustainability and consistency of the products. All products are rigorously monitored during harvest, drying and milling and analysed independently by UKAS-accredited laboratories for nutritional composition, contaminants and heavy metals.

\section{In vitro iodine bioavailability assays}

In vitro determination of the bioavailability of iodine from seaweeds is based on the simple simulation of gastric and intestinal digestion according to the method developed by Romaris-Hortas et al. ${ }^{(18)}$

Digestion was carried out in triplicate. Briefly, powdered NaHS $(0.5 \mathrm{~g})$ was added to distilled water $(20 \mathrm{ml})$, and the $\mathrm{pH}$ was adjusted to 2.0 with $6 \mathrm{~m}$-hydrochloric acid. Fresh gastric solution $(0.15 \mathrm{~g}$, pepsin $6.0 \%(\mathrm{w} / \mathrm{v})$ dissolved in $6.0 \mathrm{M}-\mathrm{HCl})$ was added to the flasks before incubation $\left(37^{\circ} \mathrm{C}\right.$ in a shaking bath at $150 \mathrm{rpm}$ for $120 \mathrm{~min})$. Digestate aliquots $(0.5 \mathrm{ml})$ were stored at $-20^{\circ} \mathrm{C}$ before the determination of iodine bioavailability. The $\mathrm{pH}$ of digestates was neutralised with $\mathrm{NaOH}$ (pH 7.5). Dialysis bags filled with $75 \mathrm{~mm}$ - piperazine-N, $\mathrm{N}^{\prime}$-bis(2-ethanesulfonic acid (PIPES) buffer $(20 \mathrm{ml})$ were placed inside each flask, along with intestinal digestion solution (pancreatin $4.0 \%(\mathrm{~m} / \mathrm{v})$ and bile salts $2.5 \%(\mathrm{~m} / \mathrm{v})$ dissolved in $0 \cdot 1 \mathrm{M}$-sodium hydrogen carbonate, $5 \mathrm{ml}$ ). The flasks were incubated at $37^{\circ} \mathrm{C}$ in a shaking water-bath at $150 \mathrm{rpm}$ for $120 \mathrm{~min}$. The enzymatic reaction was stopped by immersing the flasks in an ice water-bath. The dialysis bags were removed, and residual or non-dialysable fractions (remaining slurries in the flasks) were transferred to polyethylene vials and weighed separately. Aliquots $(1.5 \mathrm{ml})$ of the dialysable $(20 \mathrm{ml})$ and non-dialysable $(25 \mathrm{ml})$ fractions were stored at $-20^{\circ} \mathrm{C}$ before the determination of iodine bioavailability.

The colonic fermentation of digestates was carried out as described previously ${ }^{(19)}$ to determine whether iodine was trapped in the seaweed matrix after digestion. Briefly, faecal samples (16g) obtained from three healthy volunteers were homogenised using a blender $(30 \mathrm{~s})$ in a fermentation buffer $(50 \mathrm{ml})$ to obtain a $32 \%$ faecal slurry. An aliquot $(5 \mathrm{ml})$ of the non-dialysable fraction of the intestinal digestate was added to the faecal slurry $(50 \mathrm{ml})$. The bottle was purged with OFN ( $1 \mathrm{~min}$ ) and sealed and incubated in a shaking water-bath at $37^{\circ} \mathrm{C}$ and 60 strokes $/ \mathrm{min}$. Samples were taken at $t=0,2,4,6$ and $24 \mathrm{~h}$ to measure $\mathrm{pH}$ and were immediately stored at $-20^{\circ} \mathrm{C}$ before the determination of iodine bioavailability.

\section{Human iodine bioavailability study - experimental design}

The iodine bioavailability study was approved by the Ethics Committee of the Medical, Veterinary and Life Sciences College of the University of Glasgow. All participants provided written informed consent.

Healthy women aged 18-46 years, self-reporting low iodine consumption, were recruited locally through posters and word-of-mouth to participate in a cross-over iodine bioavailability study. Those with existing thyroid or gastrointestinal conditions, taking medications other than the contraceptive pill or smoking, as well as pregnant or lactating women and those planning to conceive, were excluded. Those taking dietary supplements containing iodine were also excluded. Appropriate sample size for bioequivalence/bioavailability studies varies between twelve and twenty-four subjects. According to Hauschke et al. ${ }^{(20)}$, twenty participants are required for standard $2 \times 2$ cross-over studies, with 
a bioequivalence range of $0 \cdot 8-1 \cdot 25$, using a conservative $20 \% \mathrm{CV}$ (with $\alpha=0.05$ and $\beta=0.80$ ).

The height, weight, waist circumference and blood pressure of the participants were measured after recruitment. Usual dietary intake was determined using an iodine-specific $\mathrm{FFQ}^{(21)}$. The participants were allocated at random to a treatment order (KI or seaweed first) and were asked to avoid the consumption of all iodine-rich foods (dairy products and seafood) for the duration of the study. Prospective food diaries were maintained for the duration of the study. The iodine content of participants' diet was determined by entering details of all foods in a dietary assessment software (WinDiets 2005, Robert Gordon University) using appropriate food composition tables ${ }^{(22)}$. There was a $7 \mathrm{~d}$ washout period between each leg of the cross-over intervention. The participants were asked to replicate their diet during the second leg of the study.

All urine passed on day 1 (baseline $24 \mathrm{~h}$ urine samples) was collected. On day 2, the participants were given either a seaweed supplement (NaHS, $1 \mathrm{~g}$ ) or a KI supplement (equivalent iodine content; $712 \mu \mathrm{g}$ ) to be taken fasted with a breakfast of white toast and a glass of water. Urine samples were collected for $24 \mathrm{~h}$ in fractions during the following periods: $0-2 ; 2-5$; 5-8; 8-20; 20-24h.

\section{Seaweed supplementation study - experimental design}

Healthy women aged $18-50$ years, self-reporting low iodine consumption, were recruited locally through posters and word-of-mouth to participate in a cross-over seaweed supplementation study. Those with existing thyroid or gastrointestinal conditions or taking medications other than the contraceptive pill, as well as those taking iodised dietary supplements, were excluded. None had taken part in the bioavailability study. The supplementation study was approved by the Ethics Committee of the Medical, Veterinary and Life Sciences College of the University of Glasgow. All participants provided written informed consent. The a priori sample size was calculated in G Power (Kiel University) using UIC as a primary outcome for mean difference between two groups using the Wilcoxon signed-rank test for matched pairs, assuming a logistic parent distribution. A sample size of forty-two subjects was calculated to detect (or not) an increase from the current population UIC for the target group (median $75 \mu \mathrm{g} / \mathrm{l}$, calculated mean $94 \mu \mathrm{g} / \mathrm{l}$, standard deviation $\left.80 \mu \mathrm{g} / \mathrm{l}^{(10)}\right)$ to a sufficient UIC $(100 \mu \mathrm{g} / \mathrm{ml})$, equivalent to approximately $14 \%$ increase in UIC and an effect size of 0.47 (with $\alpha=0.05$ and $\beta=0.80$ ).

The height, weight, waist circumference and blood pressure of the participants were measured at the beginning and end of the supplementation period. Usual dietary intake was determined using an iodine-specific $\mathrm{FFQ}^{(21)}$. During the run-in period, the participants were asked to maintain a $4 \mathrm{~d}$ weighed food diary. Urine samples were collected for $24 \mathrm{~h}$ on day 4 . On day 5 , the participants were given a stock of supplements and instructed to consume one capsule of NaHS daily $(0.5 \mathrm{~g} / \mathrm{d}$, equivalent to an intake of $356 \mu \mathrm{g} / \mathrm{d}$ of iodine) for $14 \mathrm{~d}$ while following their usual diet. A fasting venous blood sample was collected, and the total volume of the urine collection was measured. At the end of the supplementation period, the participants replicated the diet recorded in the $4 \mathrm{~d}$ weighed diary (days 16-19) and collected $24 \mathrm{~h}$ urine samples on the last day of supplementation (day 19). A final fasting venous blood sample was collected (day 20). All urine and plasma samples were aliquoted and stored at $-80^{\circ} \mathrm{C}$ until analysis. Compliance was checked by counting the number of capsules remaining in the container given to the participants.

\section{Urinary iodine measurements}

Urinary and digestate iodine concentrations were determined using the colorimetric Sandell-Kolthoff reaction adapted for the ninety-six-well microtitre plate, as described by Ohashi et $a l^{(23)}$, using a custom-made sealing cassette. Samples were measured in triplicates $(\mathrm{CV}<10 \%)$.

\section{Thyroid function tests}

The concentrations of TSH, thyroglobulin $(\mathrm{Tg}), \mathrm{T}_{3}$, free $\mathrm{T}_{3}$, $\mathrm{T}_{4}$ and free $\mathrm{T}_{4}$ in plasma were measured in duplicates using immunoassays (ELISA; Astra Biotech GmbH).

\section{Acceptability of the supplement}

The participants filled a self-administered questionnaire focusing on habitual frequency of consumption of seaweed products (six-point Likert scale: 'daily' to 'never'), opinions on taste (three statements; five-point Likert scale: 'strongly agree' to 'strongly disagree'), aftertaste (one statement; fivepoint Likert scale: 'strongly agree' to 'strongly disagree') and overall acceptability of seaweed as a food or a food ingredient (three statements; five-point Likert scale: 'strongly agree' to 'strongly disagree'). Open questions were used to gather information on taste, aftertaste and views on seaweed as a food ingredient.

\section{Statistical analyses}

Data are expressed as means with standard deviations or as medians with interquartile ranges (IQR) depending on normality, which was checked using the Shapiro-Wilk test. Categorical data (Likert scale) are reported using the mode and IQR. $P$ values $<0.05$ were considered to be significant. The Wilcoxon signed-rank test for matched pairs or paired $t$ test was used to assess the difference between paired groups depending on their data distribution, while the Mann-Whitney $U$ test or independent $t$ test was used to compare unrelated samples. Analyses were carried out using SPSS 18.0 (SPSS, Inc.).

\section{Results}

In vivo bioavailability study

A total of twenty-two healthy females, median age 24.5 (IQR 22-34) years, participated in the bioavailability study. 
Table 1. Characteristics of participants of the bioavailability study ( $n 22)$ (Medians and interquartile ranges (IQR); number of counts and percentages)

\begin{tabular}{|c|c|c|}
\hline & Median & IQR \\
\hline \multicolumn{3}{|c|}{ Demographic and anthropometric details } \\
\hline Age (years) & $24 \cdot 5$ & $22-34$ \\
\hline Height $(\mathrm{cm})$ & 165 & $163-167$ \\
\hline Weight (kg) & 60 & $56-70$ \\
\hline Waist circumference $(\mathrm{cm})$ & 71 & $66-77$ \\
\hline BMI $\left(\mathrm{kg} / \mathrm{m}^{2}\right)$ & 22 & $20-24$ \\
\hline \multicolumn{3}{|l|}{ Usual diet } \\
\hline Milk (mg/d) & 131 & $92-236$ \\
\hline Other dairy products (mg/d) & 115 & $81-172$ \\
\hline Seafood, including fish (mg/d) & 24 & $13-29$ \\
\hline \multirow[t]{2}{*}{ Daily iodine intake $(\mu \mathrm{g} / \mathrm{d})$} & 127 & $87-142$ \\
\hline & $n$ & $\%$ \\
\hline \multicolumn{3}{|l|}{ Ethnicity } \\
\hline White British & 6 & 27 \\
\hline White Europeans & 4 & 18 \\
\hline Other ethnicities & 12 & 55 \\
\hline \multicolumn{3}{|l|}{ Body composition } \\
\hline Overweight (BMI > $\left.25 \mathrm{~kg} / \mathrm{m}^{2}\right)$ & 3 & 14 \\
\hline Obese $\left(\mathrm{BMI}>30 \mathrm{~kg} / \mathrm{m}^{2}\right)$ & 1 & 5 \\
\hline \multicolumn{3}{|l|}{ lodine intake } \\
\hline Daily iodine intake $>140 \mu \mathrm{g} / \mathrm{d}$ & 7 & 33 \\
\hline Daily iodine intake $<140 \mu \mathrm{g} / \mathrm{d}$ & 14 & 67 \\
\hline
\end{tabular}

The sociodemographic and anthropometric characteristics of the participants are summarised in Table 1.

Dietary iodine intake was low (below $55 \mu \mathrm{g} / \mathrm{d}$ ) in each study arm throughout the bioavailability study (Table 2). The baseline median UIC, during the $24 \mathrm{~h}$ preceding the study, was 40 (IQR 24-66) $\mu \mathrm{g} / \mathrm{l}$ before seaweed supplement ingestion and 31 (IQR 19-71) $\mu \mathrm{g} / \mathrm{l}$ before KI supplement ingestion. On correcting for total urine volumes, this was found to be equivalent to 50 (IQR $40-82$ ) $\mu \mathrm{g} / 24 \mathrm{~h}$ before seaweed supplement ingestion and 48 (IQR $32-86) \mu \mathrm{g} / 24 \mathrm{~h}$ before KI supplement ingestion.

Urinary iodine excretion (in $\mu \mathrm{g} / \mathrm{l}$ per $\mathrm{h}$ ) is shown in Fig. 1 and cumulated iodine output (in $\mu \mathrm{g}$ ) is shown in Fig. 2. The peak iodine excretion occurred earlier in participants ingesting the KI supplement $(0-2 \mathrm{~h})$ that in those ingesting the seaweed supplement $(2-5 \mathrm{~h})$. The amount of iodine excreted over the $24 \mathrm{~h}$ period following ingestion was higher $(P<0 \cdot 001)$ after KI supplement ingestion ( $421 \mu \mathrm{g}$, IQR 328-526) than after seaweed supplement ingestion (239 $\mu \mathrm{g}$, IQR 199-352).

The participants were grouped according to their habitual iodine intake as either sufficient $(n 7)$ or insufficient $(n 13)$. The amount of iodine excreted in urine was calculated based on the iodine load of the NaHS capsule/KI plus the dietary iodine intake on day 3 (Table 2 ). The amount of iodine excreted was significantly higher $(P<0.001)$ after KI supplement ingestion (59\%, IQR 46-74) than after seaweed supplement ingestion (33\%, IQR 28-46). This was true for both subgroups $(P=0.009$ and $P=0.017$ for the insufficient and sufficient groups, respectively). However, although the amount of iodine excreted after KI supplement ingestion was higher in the sufficient group ( $73 v .46 \%, P=0.036$ ), there was no difference between the groups after seaweed supplement ingestion (46v. 31\%) (Table 3).

\section{In vitro bioavailability assays}

After digestion in the simulated gastric compartment, only 9.9 (SD $0 \cdot 1) \%$ of the iodine present in the sample was available and in solution. After digestion in the simulated intestinal compartment, 4.9 (SD 0.1 ) \% of the initial iodine dose present was recovered in the dialysis bag, with a further 5.0 (SD 0.0$) \%$ being recovered in the non-dialysable fraction. This indicates that approximately $90 \%$ of the iodine was still trapped in the seaweed matrix at that point and is consistent with the cumulated amount excreted in urine during the in vivo bioavailability study (up to $5 \mathrm{~h}$ after ingestion), which was approximately $12 \%$ of the dose ingested (IQR 7-15). After faecal fermentation of an aliquot of the non-dialysable fraction, $51 \cdot 2$ (SD $10 \cdot 4) \%$ of the iodine present in the sample was available and in solution.

\section{Impact of seaweed supplementation on urinary iodine concentrations}

A total of forty-two healthy females of childbearing age participated in the 2-week supplementation study. The demographic, anthropometric and dietary characteristics of the participants are summarised in Table 4.

At baseline, median UIC was well below the cut-off for iodine sufficiency $(100 \mu \mathrm{g} / \mathrm{l})$ at 78 (IQR 39-114) $\mu \mathrm{g} / \mathrm{l}$. The group average iodine intake was 110 (IQR 73-141) $\mu \mathrm{g}$, with thirty-one participants having an intake below the recommended value of $140 \mu \mathrm{g} / \mathrm{d}$. Subsequently, the participants were classified as having sufficient iodine intake $(>140 \mu \mathrm{g})$ or insufficient iodine intake $(<140 \mu \mathrm{g})$ based on their habitual iodine intake as estimated by the FFQ. There was no difference in weight, BMI and waist circumference between the subgroups with sufficient or insufficient iodine intake at baseline.

Table 2. Daily dietary iodine intake $(\mu \mathrm{g})$ according to study arm (Medians and interquartile ranges (IQR))

\begin{tabular}{lccccccccc}
\hline & \multicolumn{2}{c}{ Day 1} & & \multicolumn{2}{c}{ Day 2 } & & \multicolumn{2}{c}{ Day 3 } \\
\cline { 2 - 3 } Study arms & Median & IQR & & Median & IQR & & Median & IQR \\
\hline NaHS - KI & 54 & $32-84$ & & 45 & $29-65$ & & 39 & $28-64$ \\
$\mathrm{KI}-\mathrm{NaHS}$ & 53 & $33-58$ & & 48 & $26-91$ & & 38 & $25-65$ \\
\hline
\end{tabular}

NaHS, Napiers Hebridean Seagreens Ascophyllum nodosum. 


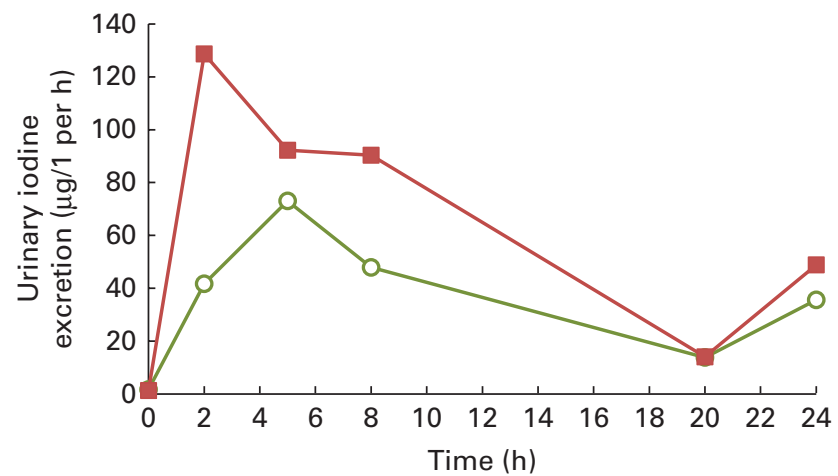

Fig. 1. Urinary iodine excretion over $24 \mathrm{~h}$ after the ingestion of a dose of $712 \mu \mathrm{g}$ of iodine from potassium iodide (ם) or Napiers Hebridean Seagreens Ascophyllum nodosum $(O)$. (A colour version of this figure can be found online at http://www.journals.cambridge.org/bjn).

After supplement ingestion, median UIC increased significantly to 140 (IQR 103-194) $\mu \mathrm{g} / \mathrm{l} \quad(P<0 \cdot 001)$. This increase in UIC differed between the sufficient and insufficient groups $(+23 \mu \mathrm{g} / \mathrm{l}$, IQR $17-66$ for the sufficient group; $+97 \mu \mathrm{g} / \mathrm{l}$, IQR $57-132$ for the insufficient group; $P=0.041$ ) and was only statistically significant in participants with insufficient habitual iodine intake $(P<0 \cdot 001)$. However, there was a significant increase in the total amount of iodine excreted over $24 \mathrm{~h}$ in both the insufficient group (from 93 (IQR $60-109)$ to 262 (IQR 198-301) $\mu \mathrm{g} / \mathrm{d} ; P<0 \cdot 001$ ) and the sufficient group (from 138 (IQR 73-157) to 214 (IQR 75-343) $\mu \mathrm{g} / \mathrm{d}$; $P<0 \cdot 041)$. There was no change in either weight or waist circumference during the supplementation study.

\section{Impact of seaweed supplementation on thyroid function}

The results of thyroid function tests are given in Table 5 . At baseline, there was a significant difference in the concentrations of $\mathrm{Tg}$ and free $\mathrm{T}_{3}$ between the sufficient and insufficient subgroups ( $P=0.047$ and $P=0 \cdot 048$, respectively). $\mathrm{Tg}$ values were within the $\mathrm{Tg}$ reference range in healthy adults $(3-40 \mu \mathrm{g} / \mathrm{l})$, but higher than the proposed cut-off for iodine sufficiency $(10 \mu \mathrm{g} / \mathrm{l})$.

The concentrations of TSH were within the normal range $(0.4-4.5 \mathrm{mIU} / 1)^{(24)}$ in all but one participant, who had a borderline TSH concentration of 5.72 (but normal free $\mathrm{T}_{4}$ concentrations).

There was no significant change in the concentrations of $\mathrm{T}_{3}$, $T_{4}$, free $T_{3}$ and free $T_{4}$ after supplement ingestion or in those of $\mathrm{Tg}$ (with values remaining over $10 \mu \mathrm{g} / \mathrm{l})^{(25)}$. However, there was a significant increase in the concentrations of TSH, from a median 1.5 (IQR $1 \cdot 2-2 \cdot 2$ ) to $2 \cdot 1$ (IQR $1 \cdot 3-2 \cdot 9$ ) mIU/1 $(P<0.001)$. This increase was significant in both the insufficient and sufficient groups ( $P=0.027$ and $P=0.006$, respectively), but more marked in those with sufficient habitual iodine intake ( $P=0.044)$. The serum concentrations of TSH did exceed the normal range in two participants $(7.3$ and $8.0 \mathrm{mIU} / \mathrm{l})$, with free $\mathrm{T}_{4}$ concentrations still being within the normal range. Although there were no significant changes in the concentrations of free $\mathrm{T}_{3}$ in the whole group, a decrease was observed in the insufficient group after supplement ingestion $(P=0 \cdot 048)$.

\section{Seaweed consumption and acceptability of the} supplement

Participants of the bioavailability and supplementation studies answered an additional questionnaire on seaweed consumption (combined $n$ 63). The participants reported that they had very rarely been exposed to seaweed as a foodstuff, with 19\% reporting that they had never consumed it knowingly; $60 \%$ of the participants reported that they had consumed it as sushi, on a monthly basis (18\%) or less often (37\%). Less than half (40\%) of the participants reported that they had consumed whole seaweed (less than twice a year). Most of the participants reported that they had never consumed lava bread (90\%) or seaweed as a tablet $(92 \%)$ or a capsule $(87 \%)$. The main reasons for low consumption were the lack of opportunity (mentioned by $64 \%$ of the participants) and lack of appeal (54\%).

The participants agreed that the taste of the supplement was acceptable when swallowed as a capsule (mode 5, median 4 , IQR 3-5) and disagreed that there was an unpleasant aftertaste (mode 2, median 2, IQR 2-4) or that the capsule was difficult to swallow (mode 1, median 2, IQR 1-2). Participants of the supplementation study who had added the seaweed to foods ( $n$ 24) neither agreed nor disagreed on the acceptability of its taste when used as an ingredient (mode 3, median 3, IQR 3-3) or its ease of use for cooking (mode 3, median 3, IQR 3-4).

The participants agreed that using the seaweed encapsulated is a better option while adding it to the diet (mode 4, median 4, IQR 4-5). The participants preferred consuming the seaweed encapsulated (71\%), as an ingredient in foods (33\%) or as a whole food (19\%). Most of the participants (67\%) held a positive view regarding the potential of seaweed as a food ingredient. The main reasons were assumed health benefits and extra nutrient supply (35\%) and flavour enhancement (24\%). A minority (7\%) held a negative view regarding the use of seaweed as a food ingredient, with taste being the main concern (75\%). The remaining participants were either unsure or had no opinion.

\section{Discussion}

The present study demonstrated that asymptomatic young women consuming diets low in seafood and dairy products do

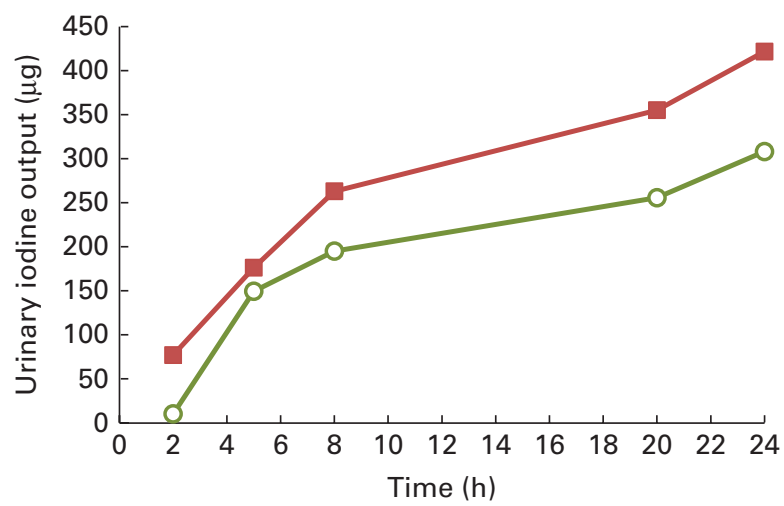

Fig. 2. Cumulated iodine output over $24 \mathrm{~h}$ after the ingestion of a dose of $712 \mu \mathrm{g}$ of iodine from potassium iodide ( $\mathbf{\square}$ ) or Napiers Hebridean Seagreens Ascophyllum nodosum (O). (A colour version of this figure can be found online at http://www.journals.cambridge.org/bjn). 
Table 3. Percentage of iodine dose excreted according to habitual iodine intake (sufficient and insufficient)

(Medians and interquartile ranges (IQR))

\begin{tabular}{lccccc}
\hline & \multicolumn{2}{c}{ Seaweed } & & \multicolumn{2}{c}{ KI } \\
\cline { 2 - 3 } \cline { 6 - 6 } & Median & IQR & & Median & IQR \\
\hline Insufficient $(n$ 13) & $31^{\mathrm{a}}$ & $30-44$ & & $46^{\mathrm{b}}$ & $40-72$ \\
Sufficient $(n$ 7) & $46^{\mathrm{a}}$ & $33-49$ & & $73^{\mathrm{b}}$ & $64-77$ \\
All $(n$ 22) & $33^{\mathrm{a}}$ & $28-46$ & & $59^{\mathrm{b}}$ & $46-74$ \\
\hline
\end{tabular}

${ }^{a, b}$ Median values with unlike superscript letters were significantly different ( $\Delta$ pre-supplementation - post-supplementation) between the groups $(P<0.05)$.

indeed display biochemical evidence of quite marked iodine deficiency. It also demonstrated how an acceptable/palatable commercially available seaweed product could boost the iodine intake of a group of mostly iodine-insufficient women, without a deleterious impact on their thyroid function. Even in an iodine-sufficient population (UIC $>100 \mu \mathrm{g} / \mathrm{l}$ ), the consumption of this product (or a product of similar quality and traceability) would not be contraindicated because the urinary iodine concentrations attained would not exceed $500 \mu \mathrm{g} / \mathrm{l}$.

Daily intake of an encapsulated seaweed (NaHS) was effective at increasing the UIC of a group of females after a 2-week supplementation period, with a slight increase in TSH concentrations occurring after seaweed supplement ingestion. The results of the present study are in agreement with those of the study carried out by Teas et al. ${ }^{(26)}$, who supplemented iodine-replete healthy post-menopausal women with Alaria esculenta capsules for 7 weeks ( $475 \mu \mathrm{g}$ iodine/d), and those of the study carried out by Clark et al. ${ }^{(27)}$ (kelp, $1 \mathrm{~g}$ iodine/d for 6 weeks). The concentrations of TSH remained within the normal range in all but two participants, with no change being observed in the concentrations of the thyroid hormones, whereas Clark et ll $^{(27)}$ observed a decrease in the concentrations of total $\mathrm{T}_{3}$ after supplementation. Tg values remained higher than the proposed $10 \mu \mathrm{g} / \mathrm{l}$ cut-off for iodine insufficiency, even after supplementation, which might be indicative of a lag period for $\mathrm{Tg}$ values to fall within the iodine sufficiency range after achieving iodine-sufficient status.

The iodine present in NaHS was bioavailable, although to a lesser extent (30\%) than reported previously by Aquaron et al. ${ }^{(28)}$ (90-100\% for iodine-sufficient women and $62-85 \%$ for iodine-insufficient women over $48 \mathrm{~h}$ ) or Teas et al. ${ }^{(26)}$ ( $60 \%$ for iodine-sufficient women over $48 \mathrm{~h}$ ). This may be directly related to the shorter $(24 \mathrm{~h})$ urine collection duration in the present study and the type of seaweed used in other studies (Gracilaria verrucosa, Laminaria byperborea and A. esculenta). Incomplete collections are also a possible explanation. We found a difference in the amounts of iodine excreted between those with either sufficient or insufficient iodine intake, as described previously ${ }^{(28)}$. This is consistent with the generally held view that most of the iodine will be excreted in urine if iodine stores are replete. In vitro digestion confirmed the limited release of iodine from the seaweed matrix in the first gastric and intestinal phases of simulated digestion. We found that colonic fermentation of seaweed is important to free iodine from the seaweed matrix, with the mechanism being reliant on the fermentation of the polysaccharide matrix ${ }^{(29)}$ or metabolism of organic iodine ${ }^{(18)}$. Therefore, the seaweed matrix may delay iodine absorption (compared with KI), with iodine being released from the food over a longer period. Impact of further processing such as cooking needs to be taken into consideration if seaweeds are being used as ingredients, as it would lead to partial loss via evaporation ${ }^{(17,30)}$.

Several studies have reported iodine-insufficient populations to be diagnosed with iodine-induced hyperthyroidism or hypothyroidism following high iodine intake ${ }^{(31-34)}$; however, a 2-week iodine supplementation with up to $500 \mu \mathrm{g} / \mathrm{d}$ has been found to have no impact on the results of thyroid function tests in euthyroid subjects ${ }^{(35)}$. The upper tolerable limit of iodine intake in healthy individuals has been defined as $1.1 \mathrm{mg} / \mathrm{d}$ in the USA and $600 \mu \mathrm{g} / \mathrm{d}$ in the European Union $^{(36,37)}$. Although epidemiological evidence has linked high daily seaweed/iodine intake to higher thyroid cancer risk in Japan ${ }^{(38)}$, this observation is not supported by experimental studies in rats with chronic high iodine intake (up to $1 \mathrm{~g} / \mathrm{l}$ in drinking-water $)^{(39)}$. The thyroid gland can adapt to excessive iodine intake after initial diminution in the excretion of thyroid hormones due to the Wolff-Chaikoff effect. This effect has been demonstrated to cause a longer-lasting suppression on the thyroid gland in those ingesting excess amounts of seaweeds ${ }^{(40)}$. Restriction of seaweed intake has been found to be able to reverse iodine-induced goitre and transient hypothyroidism ${ }^{(41)}$.

Reports of widespread iodine insufficiency in Britain and other European countries, the renewed interest in iodine nutrition and the lack of iodine prophylaxis in the UK represent an opportunity to use seaweeds as foodstuffs. Iodine insufficiency results from

Table 4. Characteristics of participants of the 2-week supplementation study ( $n$ 42)

(Medians and interquartile ranges (IQR); number of counts and percentages)

\begin{tabular}{|c|c|c|}
\hline & Median & IQR \\
\hline \multicolumn{3}{|c|}{ Anthropometric and demographic details } \\
\hline Age (years) & $27 \cdot 0$ & $22-37$ \\
\hline Height $(\mathrm{cm})$ & 164 & $162-168$ \\
\hline Weight (kg) & 62 & $57-71$ \\
\hline Waist circumference $(\mathrm{cm})$ & 72 & $67-82$ \\
\hline BMI $\left(\mathrm{kg} / \mathrm{m}^{2}\right)$ & 23 & $21-26$ \\
\hline \multicolumn{3}{|l|}{ Usual diet } \\
\hline Milk (mg/d) & 180 & $79-259$ \\
\hline Other dairy products $(\mathrm{mg} / \mathrm{d})$ & 71 & $37-159$ \\
\hline Seafood, including fish $(\mathrm{mg} / \mathrm{d})$ & 20 & $8-38$ \\
\hline \multirow[t]{2}{*}{ Daily iodine intake $(\mu \mathrm{g} / \mathrm{d})$} & 110 & $70-139$ \\
\hline & $n$ & $\%$ \\
\hline \multicolumn{3}{|l|}{ Ethnicity } \\
\hline White British & 25 & 60 \\
\hline White Europeans & 9 & 21 \\
\hline Other ethnicities & 8 & 19 \\
\hline \multicolumn{3}{|l|}{ Body composition } \\
\hline Overweight (BMI > 25 kg/m²) & 10 & 24 \\
\hline Obese $\left(\mathrm{BMI}>30 \mathrm{~kg} / \mathrm{m}^{2}\right)$ & 4 & 10 \\
\hline \multicolumn{3}{|l|}{ lodine intake } \\
\hline Daily iodine intake $>140 \mu \mathrm{g} / \mathrm{d}$ & 11 & 26 \\
\hline Daily iodine intake $<140 \mu \mathrm{g} / \mathrm{d}$ & 31 & 74 \\
\hline
\end{tabular}


a low intake of dairy products (especially milk, the consumption of which has been steadily decreasing since $1975^{(42)}$ ) and seafood (the consumption of which is low in the UK population at $\left.37 \mathrm{~g} / \mathrm{d}^{(43)}\right)$. Consumption of iodised salt is the main route of iodine prophylaxis worldwide, but there is still some concern, among clinical and public health professionals, that attributing a positive, health-promoting characteristic to salt may blunt the public health effort towards salt reduction in relation to the prevention of CVD. This topic, to synergise salt reduction and iodine fortification agendas, has been debated in a recent joint WHO/ICCIDD meeting ${ }^{(44)}$. With the usage of table salt decreasing in the UK following successful public health campaigns, it may be contradictory to portray salt as a vehicle for iodine. Viable alternatives to increase iodine status include fortification of staple foods with seaweeds, which have successfully been incorporated previously in a nutritionally balanced pizza, designed in the context of health-by-stealth improvement of ready meals. Seaweed inclusion enabled to reduce the $\mathrm{Na}$ content of the product while improving nutritional content, without compromising the taste or appearance ${ }^{(45)}$. Given that iodine is extensively stored in the thyroid, it can safely be consumed intermittently, which makes seaweed use in a range of foods attractive and occasional seaweed intake sufficient to ensure iodine sufficiency.

Seaweed consumption in most Western cultures has been low, due to low availability in the market and poor consumer awareness regarding potential health benefits ${ }^{(46)}$. The benefits of incorporating seaweed isolates into the habitual diet go further than addressing iodine deficiency, with impact of seaweed consumption on serum oestradiol, reduction of the glycaemic response to a carbohydrate load, and increased satiety via lowered gastric emptying. These aspects may be relevant for the development of functional foods for weight management ${ }^{(47-51)}$. Incorporation of seaweeds in bread has been found to have no impact on taste or appearance ${ }^{(46)}$. Trade prices are such that the additional cost per loaf would be minimal considering that seaweeds are iodine rich and that little amounts would be required.

The contaminant and heavy metal content of seaweeds is sometimes a concern, especially in retailed products with poor traceability and limited compositional analysis, as consumption may expose the consumer to heavy metals such as organic/inorganic $\mathrm{As}^{(52)}$. Water quality is important for seaweed quality, and France is the only European country with specific regulations on the use of seaweeds as vegetables ${ }^{(30)}$. The seaweed used in the present study (NaHS) was grown in Scottish Grade A pristine water (SEPA/SNH evaluation) and produced to Human Food Seaweed ${ }^{\mathrm{TM}}$ standards (patents pending). Compositional analysis, carried out on every batch, revealed no contaminants and heavy metals to be present below the threshold levels. This is important if seaweeds become more commonly used ingredients in processed foods.

In conclusion, the answers to the research questions on which the present study is based are follows:

(1) Iodine bioavailability from the encapsulated seaweed was low in the group of women studied. The seaweed matrix may be a key factor responsible for this low bioavailability. 
(2) Daily intake of $0.5 \mathrm{~g}$ of NaHS increased urinary iodine concentrations to $140 \mu \mathrm{g} / \mathrm{l}$ in the study group. The concentrations of TSH increased slightly, within the normal range in all but two participants. The increase in TSH concentrations may be associated with iodineinduced hypothyroidism, especially in those with replete iodine stores, although no change in the concentrations of thyroid hormones was observed ${ }^{(40)}$.

(3) The participants reported that the encapsulated seaweed had an acceptable taste and was easy to use and were positive about the use of seaweeds as food ingredients.

The conclusions drawn would have been strengthened with a randomised, controlled cross-over study design, longer exposure time and reassessment of iodine status and thyroid function after the end of the intervention, but that would demand an impractical duration of high tolerance from the volunteers. It would be of value to repeat the analysis of biochemical aspects in different subject groups. The influence of the seaweed matrix on bioavailability will be an important factor to consider if seaweeds are being incorporated in cooked and uncooked staple foods. A large-scale survey needs to be carried out to properly investigate consumers' attitudes towards seaweed use in processed foods and cuisine in general.

\section{Acknowledgements}

E.C. secured the funding, designed the study and supervised its execution. Z. F. M., F. C., B. T. and E. C. collected and analysed the data. E. C. and M. E. J. L. prepared the manuscript, which was revised and approved by all authors. The authors are grateful to Ms Maria Bouga for revising the manuscript.

The present study was funded by a Technology Strategy Board Feasibility Grant through collaboration between the University of Glasgow and Napiers the Herbalists in partnership with the Seaweed Health Foundation.

\section{References}

1. Velasco I, Carreira M, Santiago P, et al. (2009) Effect of iodine prophylaxis during pregnancy on neurocognitive development of children during the first two years of life. J Clin Endocrinol Metab 94, 3234-3241.

2. Abalovich M, Gutierrez S, Alcaraz G, et al. (2002) Overt and subclinical hypothyroidism complicating pregnancy. Thyroid 12, 63-68.

3. Montoro M, Collea JV, Frasier SD, et al. (1981) Successful outcome of pregnancy in women with hypothyroidism. Ann Intern Med 94, 31-34.

4. World Health Organization (2007) Assessment of Iodine Deficiency Disorders and Monitoring Their Elimination. A Guide for Programme Managers. Geneva: United Nations Children's Fund, International Council for the Control of Iodine Deficiency Disorders.

5. EFSA NDA Panel (2014) Scientific opinion on dietary reference values for iodine. EFSA J 12, 3660

6. Delange F \& Lecomte P (2000) Iodine supplementation benefits outweigh risks. Drug Saf 22, 89-95.

7. Haldimann M, Alt A, Blanc A, et al. (2005) Iodine content of food groups. J Food Compos Anal 18, 461-471.
8. Phillips D (1997) Iodine, milk, and the elimination of endemic goitre in Britain: the story of an accidental public health triumph. J Epidemiol Community Health 51, 391-393.

9. Vanderpump MPJ, Lazarus JH, Smyth PP, et al. (2011) Iodine status of UK schoolgirls: a cross-sectional survey. Lancet 377, 2007-2012.

10. Lampropoulou M, Lean M \& Combet E (2012) Iodine status of women of childbearing age in Scotland. Proc Nutr Soc 71, E143.

11. Glinoer D (2004) The regulation of thyroid function during normal pregnancy: importance of the iodine nutrition status. Best Pract Res Clin Endocrinol Metab 18, 133-152.

12. Bath SC, Steer CD, Golding J, et al. (2013) Effect of inadequate iodine status in UK pregnant women on cognitive outcomes in their children: results from the Avon Longitudinal Study of Parents and Children (ALSPAC). Lancet 382, 331-337.

13. Mian C, Vitaliano P, Pozza D, et al. (2009) Iodine status in pregnancy: role of dietary habits and geographical origin. Clin Endocrinol 70, 776-780.

14. Olsen SO (2003) Understanding the relationship between age and seafood consumption: the mediating role of attitude, health involvement and convenience. Food Qual Prefer 14, 199-209.

15. Kenicer G, Bridgewater S \& Milliken W (2000) The ebb and flow of Scottish seaweed use. Botanical J Scotland 52, 119-148.

16. Norman JA, Pickford CJ, Sanders TW, et al. (1988) Human intake of arsenic and iodine from seaweed-based food supplements and health foods available in the UK. Food Addit Contam 5, 103-109.

17. Teas J, Pino S, Critchley A, et al. (2004) Variability of iodine content in common commercially available edible seaweeds. Thyroid 14, 836-841.

18. Romaris-Hortas V, Garcia-Sartal C, del Carmen BarcielaAlonso M, et al. (2011) Bioavailability study using an in-vitro method of iodine and bromine in edible seaweed. Food Chem 124, 1747-1752.

19. Edwards CA, Gibson G, Champ M, et al. (1996) In vitro method for quantification of the fermentation of starch by human faecal bacteria. J Sci Food Agric 71, 209-217.

20. Hauschke D, Steinijans VW, Diletti E, et al. (1992) Sample size determination for bioequivalence assessment using a multiplicative model. J Pharmacokinet Biopharm 20, 557-561.

21. Combet E \& Lean M (2014) Validation of a short food frequency questionnaire specific for iodine in UK females of childbearing age. J Hum Nutr Diet (epublication ahead of print version 13 March 2014).

22. McCance RA \& Widdowson EM (2002) The Composition of Foods, 6th summary ed. London/Cambridge, UK: Food Standards Agency/Royal Society of Chemistry.

23. Ohashi T, Yamaki M, Pandav CS, et al. (2000) Simple microplate method for determination of urinary iodine. Clin Chem 46, 529-536.

24. Association of Clinical Biochemists, British Thyroid Foundation and British Thyroid Association (2006) UK Guidelines for the Use of Thyroid Function Tests. www.british-thyroidassociation.org/info-for-patients/Docs/TFT_guideline_final_ version_July_2006.pdf

25. Vejbjerg P, Knudsen N, Perrild H, et al. (2009) Thyroglobulin as a marker of iodine nutrition status in the general population. Eur J Endocrinol 161, 475-481.

26. Teas J, Braverman LE, Kurzer MS, et al. (2007) Seaweed and soy: companion foods in Asian cuisine and their effects on thyroid function in American women. J Med Food 10, $90-100$ 
27. Clark CD, Bassett B \& Burge MR (2003) Effects of kelp supplementation on thyroid function in euthyroid subjects. Endocr Pract 9, 363-369.

28. Aquaron R, Delange F, Marchal P, et al. (2002) Bioavailability of seaweed iodine in human beings. Cell Mol Biol 48, 563-569.

29. Michel C, Lahaye M, Bonnet C, et al. (1996) In vitro fermentation by human faecal bacteria of total and purified dietary fibres from brown seaweeds. Br J Nutr 75, 263-280.

30. Mabeau S \& Fleurence J (1993) Seaweed in food-products biochemical and nutritional aspects. Trends Food Sci Technol 4, 103-107.

31. Roti E \& Degli Uberti E (2001) Iodine excess and hyperthyroidism. Thyroid 11, 493-500.

32. Camargo RYA, Tomimori EK, Neves SC, et al. (2008) Thyroid and the environment: exposure to excessive nutritional iodine increases the prevalence of thyroid disorders in Sao Paulo, Brazil. Eur J Endocrinol 159, 293-299.

33. Emder PJ \& Jack MM (2011) Iodine-induced neonatal hypothyroidism secondary to maternal seaweed consumption: a common practice in some Asian cultures to promote breast milk supply. J Paediatr Child Health 47, 750-752.

34. Leung AM \& Braverman LE (2012) Iodine-induced thyroid dysfunction. Curr Opin Endocrinol Diabetes Obes 19, 414-419.

35. Paul T, Meyers B, Witorsch RJ, et al. (1988) The effect of small increases in dietary iodine on thyroid function in euthyroid subjects. Metabolism 37, 121-124.

36. Flynn A, Moreiras O, Stehle P, et al. (2003) Vitamins and minerals: a model for safe addition to foods. Eur J Nutr 42, 118-130.

37. Goldhaber SB (2003) Trace element risk assessment: essentiality vs. toxicity. Regul Toxicol Pharmacol 38, 232-242.

38. Michikawa T, Inoue M, Shimazu T, et al. (2012) Seaweed consumption and the risk of thyroid cancer in women: the Japan Public Health Center-based Prospective Study. Eur J Cancer Prev 21, 254-260.

39. Takegawa K, Mitsumori K, Onodera H, et al. (2000) Studies on the carcinogenicity of potassium iodide in F344 rats. Food Chem Toxicol 38, 773-781.

40. Markou K, Georgopoulos N, Kyriazopoulou V, et al. (2001) Iodine-induced hypothyroidism. Thyroid 11, 501-510.
41. Zava TT \& Zava DT (2011) Assessment of Japanese iodine intake based on seaweed consumption in Japan: a literaturebased analysis. Thyroid Res $\mathbf{4}, 14$.

42. Elwood PC (2005) Time to value milk. Int J Epidemiol 34 $1160-1162$.

43. Department of Health and The Food Standards Agency (2011) National Diet and Nutrition Survey Headline Results from Years 1 and 2 (Combined) of the Rolling Programme (2008/2009-2009/10). London: Food Standards Agency.

44. World Health Organization (2014) Salt Reduction and Iodine Fortification Strategies in Public Health: Report of a Joint Technical Meeting Convened by the World Health Organization and The George Institute for Global Health in Collaboration with the International Council for the Control of Iodine Deficiency Disorders Global Network, Sydney, Australia, March 2013. Geneva: World Health Organization.

45. Combet E, Jarlot A, Aidoo KE, et al. (2013) Development of a nutritionally balanced pizza as a functional meal designed to meet published dietary guidelines. Public Health Nutr (epublication ahead of print version 28 October 2013).

46. Kadam SU \& Prabhasankar P (2010) Marine foods as functional ingredients in bakery and pasta products. Food Res Int 43, 1975-1980.

47. Lamela M, Anca J, Villar R, et al. (1989) Hypoglycemic activity of several seaweed extracts. J Ethnopharmacol 27 , 35-43.

48. Goni I, Valdivieso L \& Garcia-Alonso A (2000) Nori seaweed consumption modifies glycemic response in healthy volunteers. Nutr Res 20, 1367-1375.

49. Teas J, Hurley TG, Hebert JR, et al. (2009) Dietary seaweed modifies estrogen and phytoestrogen metabolism in healthy postmenopausal women. J Nutr 139, 939-944.

50. Gupta S \& Abu-Ghannam N (2011) Bioactive potential and possible health effects of edible brown seaweeds. Trends Food Sci Technol 22, 315-326.

51. Hall AC, Fairclough AC, Mahadevan K, et al. (2012) Ascophyllum nodosum enriched bread reduces subsequent energy intake with no effect on post-prandial glucose and cholesterol in healthy, overweight males. A pilot study. Appetite 58, 379-386.

52. Rose M, Lewis J, Langford N, et al. (2007) Arsenic in seaweed-forms, concentration and dietary exposure. Food Chem Toxicol 45, 1263-1267. 